\title{
Using Mixed Methods to Explore Older Residents' Physical Activity and Experiences of Community Active Aging Friendliness
}

Deborah H. John ${ }^{1,{ }^{+}, *}$, Patrick Abi Nader ${ }^{2,+}$, Katherine Gunter ${ }^{1,+}$

1. Oregon State University, 106 Ballard Hall, Corvallis, OR 97331, USA; E-Mails: Deborah.John@oregonstate.edu; Kathy.Gunter@oregonstate.edu

2. Centre de formation médicale du Nouveau-Brunswick, Université de Moncton, Moncton, New Brunswick, Canada; E-Mail: patrick.abinader@yahoo.com

+ These authors contributed equally to this work.

* Correspondence: Deborah H. John; E-Mail: Deborah.John@oregonstate.edu

Academic Editor: James S. Powers

OBM Geriatrics

2020, volume 4, issue 1

doi:10.21926/obm.geriatr.2001098
Received: October 29, 2018

Accepted: December 31, 2019

Published: January 06, 2020

\begin{abstract}
Physical inactivity is the fourth leading risk factor for global mortality and as such, it is critical that physical activity guidelines for health consider equitable access to physical activity opportunities for all, including those aged 65 years and older. The purpose of this study was to examine the intersections of attributes of older people (e.g. income, gender, age, health, physical activity) and attributes of the places they live (e.g. rurality, public transit, sidewalks, parks, community centre) to explain older adults' likelihood of participating in physical activities recommended for health. The study employed a sequential mixed-methods design. We examined the interplay of self-reported walking and exercise behaviours in a representative sample of independent, older adult ( $n=126$; age 65 years and older) residents with physical activity features of their rural $(n=3)$ and urban $(n=3)$ communities. Computed logistic regressions models predicted survey respondents' reports of walking and exercise by community type. Quantitative findings were integrated with voiced experiences of community features as qualitative determinants of active aging provided by adult residents ( $n=237$; ages 50 and older). Qualitative data were coded and analysed using constant
\end{abstract}

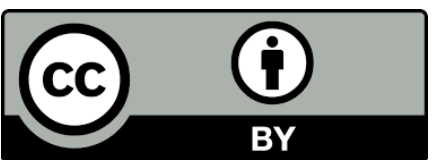

(c) 2020 by the author. This is an open access article distributed under the conditions of the Creative Commons by Attribution License, which permits unrestricted use, distribution, and reproduction in any medium or format, provided the original work is correctly cited. 
comparison triangulation across data sources. Qualitative data consisted of mapped photographs of observable determinants, physical activity supports and barriers, and transcribed focus group narratives generated by local residents. Older adults living in more urban (vs. rural) communities reporting good health and higher income had greater odds of walking around their neighbourhood $(p<0.001)$. Women (vs. men) reporting good health and higher income had greater odds $(p<0.05)$ of exercising regardless of community type. Rural (vs. urban) communities were described as having fewer available, accessible, and affordable supports, and more barriers for walking and exercising. Our data suggest active aging initiatives should include socio-environmental strategies and address resource inequities to enable participation across geographic, economic, gender, and health status differences among older adults. In particular, living in a rural place, being low-income and of poor health were associated with lower odds of walking or doing other forms of exercise, fewer supports and more socio-environmental barriers to active aging for older adults in our study.

\section{Keywords}

Active aging; built environment; photomapping; health equity

\section{Introduction}

The World Health Organization (WHO) identifies physical inactivity as a risk factor for global mortality, and recommends older adults participate in prescribed amounts of physical activity to improve health, and reduce risks for chronic disease, depression and cognitive decline [1]. In the United States (U.S.), Healthy People 2020 has physical activity objectives that include 1) increasing the proportion of adults who meet current U.S. guidelines for aerobic and muscle-strengthening physical activity, and 2) implementing policies for the community environment that enhance access to and availability of physical activity supports [2]. One strategy to support achieving the Healthy People 2020 goals was through the 2016 U.S. Surgeon General's Step It Up! A Call to Action to Promote Walking and Walkable Communities initiative which endorsed being physically active, and walking in particular, as well as calling for improved access to safe and accessible community walking venues [3]. Physical activity disparities among rural relative to urban residents have been suggested as an important contributor to rural-urban health disparity [4]. Whether this strategy is optimal for older adults, particularly those who live in rural communities is not well understood.

Adults aged 65 and over are among the fastest growing and least physically active age group in the U.S. [5]. For example, in Oregon, by 2020 the population of adults aged 75 years and older is expected to increase by at least 175 percent in nine counties, including Clackamas County where the data presented here were collected [6]. This aging demographic reports a strong desire to reside and engage in community during their older age, or "age in place" [7]. Give the importance of physical activity to disease prevention and management, it is important to assess whether communities support active aging. Clackamas County is characterized as "metro" [8] and includes a portion of Oregon's largest metropolitan urban growth boundary. At the time of this study, Clackamas County was home to a population of 375, 994 (based on US 2010 census data). Yet, it is 
geographically a mostly rural place [9] with about $95 \%$ of the land outside of the metro boundary. Approximately $28 \%$ of residents live in small rural cities and remote unincorporated farming and forest communities, and Clackamas County is the only metro county with identified unmet "rural" healthcare needs [10]. These socio-environmental disparities have the potential to burden public and personal resources as the population ages.

Meeting the needs of aging populations where they live may be a viable strategy to aging in place. Step It Up! recognizes that everyone should have access to spaces and places that make walking or being active in other ways safe and easy - whether urban, suburban, or rural communities [3]. Creating and improving community places that reinforce and support healthy habits as the behavioural default enhances health and well-being for people of all ages [11]. To do this requires applying health behaviour models that examine individuals' behaviours in the context of the environments where they live, age, work, and recreate [12, 13]. Maibach and colleagues (2007) proposed the "People and Places" framework, which is an applied ecological model of public health action [13]. Their framework for action considers how the attributes of people and places interact across multiple spheres of influence. These interactions work across spheres to structure the health of community groups, populations, and environments. The purpose of this study was to apply this framework and address the question: how do different attributes of older people (e.g. gender, income status, residential location, ability), many of which are socially determined, interplay with the socio-environmental attributes of the places they live (e.g. public transit, sidewalks, parks and trails, community centers) to facilitate physically active aging? Our aim was to elucidate how older people's ability or inability to meet physical activity recommendations and other calls to action for physically active aging may be supported or hindered by the interplay of people and community context, that is the policies, systems, and environments to which they are exposed where they live and age.

\section{Materials and Methods}

A subset of data collected from January 2011 to July 2012 in the engAGE in Community inititiative [14] were utilized to examine these secondary research questions. Data were measured with quantitative and qualitative research methods and analysed using appropriate approaches for a mixed-methods study (i.e. explanatory sequential design) [15] pictured in Figure 1.

In the initial study [14], a representative sample of adults over 21 years of age from Clackamas County, Oregon responded to a quantitative survey measuring perceived availability and importance of a set of age-friendly community features [16], self-reported lifestyle behaviours and general health. The quantitative phase was followed by prioritized recruitment of adults aged 50 and older who were engaged in the qualitative phase and mobilized for participatory assessments in their local communities involving photographing, geographically mapping and discussing socioenvironmental attributes [14]. In the qualitative phase, as recommended by Viswanathan and colleagues (2004) [17], participatory action research (PAR) tools were employed to empower people in communities to determine socio-environmental supports and barriers to aging in place, and to use their voices and vision to encourage and enact change. For this study, we retained the initial mixed methods study design. A secondary quantitative analysis of the relationships between selected survey items, self-reported physical activities (walking and exercising) and perceptions of physical activity-related attributes of the community (rural, urban) where they reside, was 
conducted using a subsample of older adults $(n=126)$. The quantitative phase preceded secondary qualitative analyses of data generated from adult (ages 50 and over) residents' experiential encounters of community features qualified as supporting or hindering their habitual physical activity behaviours. The mixed method design, which was social ecologically grounded [13], enabled an interpretative explanation of the complex interplay between physical activity attributes of people and characteristics of place.

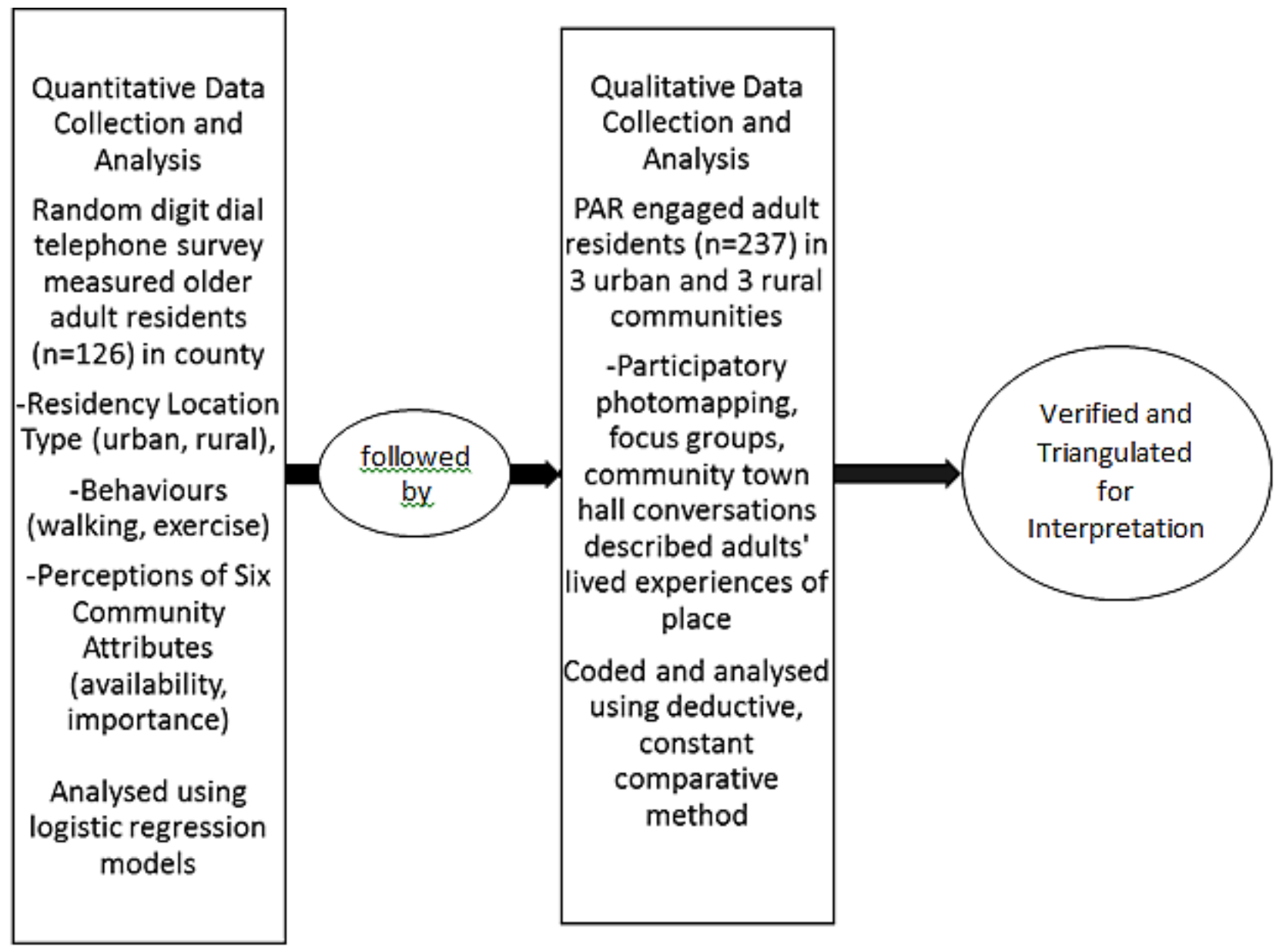

Figure 1 Mixed methods explanatory sequential design.

Study protocol \#4871 was approved by Oregon State University's Institutional Review Board. Provisions to protect the privacy of participating communities and anonymity of data were assured and maintained.

\subsection{Quantitative Telephone Survey}

The quantitative data for the current study was extracted from a needs assessment telephone survey originally developed in a collaborative effort between university researchers and county partners to evaluate future place-based aging and disability services [14]. The self-report measure was designed to assess adult residents' perceived availability and importance of community resources (e.g. housing, public transportation, sidewalks), health status and quality of life as they related to the attributes of the community (e.g. using public transit, neighbourhood walking). Survey items were adapted from "age-friendly" assessments previously developed for urban [16] 
and rural [18] communities, or selected from the U.S. Behavioural Risk Factor Surveillance System Survey Questionnaire [19]. The final 32-item survey was administered by a university survey research center, using computer-assisted telephone interviewing software and trained interviewers.

Adult residents of Clackamas County ( $n=387$; mean age 61 (21-93) years) responded to a random digit dialing telephone survey. At the time of the study Clackamas County had a sample of 2849 phone records representing the geographic and age distribution of the adult population excluding those in assisted living, residential care and nursing facilities. While thinking of their community, respondents rated a series of statements depicting age-friendly characteristics. For example, participants would respond verbally to a read statement: "My community is walkable with sidewalks and paths that are maintained. Do you strongly disagree, disagree, agree, or strongly agree with that statement?" Respondents were also asked to rate the importance [to them] of each characteristic in response to a follow-up question: "And how important is that to you, not important, somewhat important, important, or very important?" A four-point Likert-like scale was used for all items with response options varying by item. After responding to the primary questions, survey participants responded to a series of demographic, household and community (size/type), and general health and behavioural items. Over sampling assured adequate representation of the target population (adults aged +65 years).

For this study a subsample of adults age +65 years $(n=126)$ were examined. Specific survey items of interest included: 1) "My community is walkable with sidewalks and paths that are maintained"; 2) "There is adequate public transportation in my community"; 3) "How often do you walk around your neighbourhood?" and 4) "How often do you engage in physical activities or exercises to improve strength and balance?" To examine the relationship between self-reported walking and exercise behaviours of older adult residents and physical activity attributes of communities, we conducted two logistic regression models. Model 1 investigated the association of residency location with respondent's self-reported participation in walking around their neighbourhood. Model 2 assessed the association of residency location with respondent's selfreported exercising (for strength and balance). Both models were controlled for age, sex, selfreported health status, and income. Both outcomes were originally coded on a four-point scale ( $1=$ Never, $2=$ Seldom, 3= Frequently, $4=$ Always), but to conduct the logistic regression models they were transformed to a binary variable $(0=$ Never/ Seldom, and $1=$ Frequently/ Always $)$. The variable measuring residency location originally had 5 categories ( $1=$ Urban 50,000 or more people, $2=$ suburb 10,00 to 50,000 people, $3=$ small town 2,500 to 10,000 people, $4=$ small rural town less than 2,500 people, and $5=$ remote rural agricultural or woodlands). We transformed this variable into a binary variable $(0=$ urban/ suburb, $1=$ small town/ small rural town/ remote rural agricultural or woodlands). The variable representing self-reported health status was also transformed into a binary variable ( $0=$ Poor/ Fair, $1=$ Good/ Excellent). Finally, annual household income was categorized into four categories $(1=<\$ 25,000,2=\$ 25,000-<\$ 50,000,3=\$ 50,000-<$ $\$ 100,00$, and $4=\geq \$ 100,000)$. All data management and analysis processes were conducted in Stata IC/12.1 (2011) [20].

\subsection{Qualitative MAPPS ${ }^{m}$ (Mapping Assets using Participatory Photographic Surveys)}


MAPPS $^{\mathrm{TM}}$ is a PAR tool developed by John and Gunter (2015) [14], that integrates community outreach and engagement principles with community asset surveys using participatory photo mapping [21] and facilitated community conversations [22]. MAPPS ${ }^{\text {тM }}$ provides visualized data in the form of photographs and maps that elicit residents' reflective and collective narratives when displayed. The narratives explain residents' lived experiences of community qualities and elucidate community readiness [23] to address local health and place concerns. Access into communities was supported by local community champions, typically public sector sponsors (e.g., senior services) vested in improving community liveability. A purposive sample of middle (age 50-64) and older (age 65 and over) adult residents were recruited from each community, using targeted communications and snowball sampling, to voluntarily participate in MAPPS ${ }^{\text {TM }}$ activities. Participants reflected the residential population most concerned with aging and place issues, as well as local sector stakeholders. Local participants were mobilized to explore community physical, social, and service attributes, trained to gather information using qualitative tools, and participated as members of the community-based PAR team. During the initial 18-month study, environmental data, geocoded photographs and transcribed focus group narratives, were collected by adult residents, age 50 and older $(n=237)$, in six communities geographically isolated and on a rural-urban continuum ranging from more rural $(n=3)$ to more urban $(n=3)$.

Figure 2 illustrates MAPPS ${ }^{\mathrm{TM}}$ activities as described here, and in detail elsewhere [14]. Local PAR teams were engaged and received training to conduct data collection by using participatory photo mapping (PPM) [21] in their residential community. Prior studies used PPM to examine neighbourhood health and safety with youth [21] and rural physical activity friendliness with adults [24]. Study staff provided and trained community team members to use photography and camera-enabled GPS (global positioning system) units to photomap the community features they regularly encountered. Mappers annotated whether they perceived the photographed features as age-friendly supports or barriers and why on pen-and-paper photo survey worksheets while in the field.

Members of PAR teams reconvened two weeks after individually mapping their communities for a focus group to discuss and select photos for presentation during the community conversation. Two weeks after the focus group, a community-based university researcher co-facilitated a community conversation, which included a locally-hosted dinner open to all community members, presentation and reflective dialogue. People thoughtfully discussed their unique and shared experiences of displayed feature photographs, the data collected by mappers, which was captured and scribed verbatim as narrative data. Narratives were examined qualitatively using facilitated guided discovery [25] to give meaning to the disparate experiences of individuals and groups related to utility, accessibility and affordability of locally identified community attributes. Our PAR approach allowed for systematic gathering and reporting of information about and with residents to explore and explain how and why local community attributes support or limit residents' abilities to age actively in place [14]. 


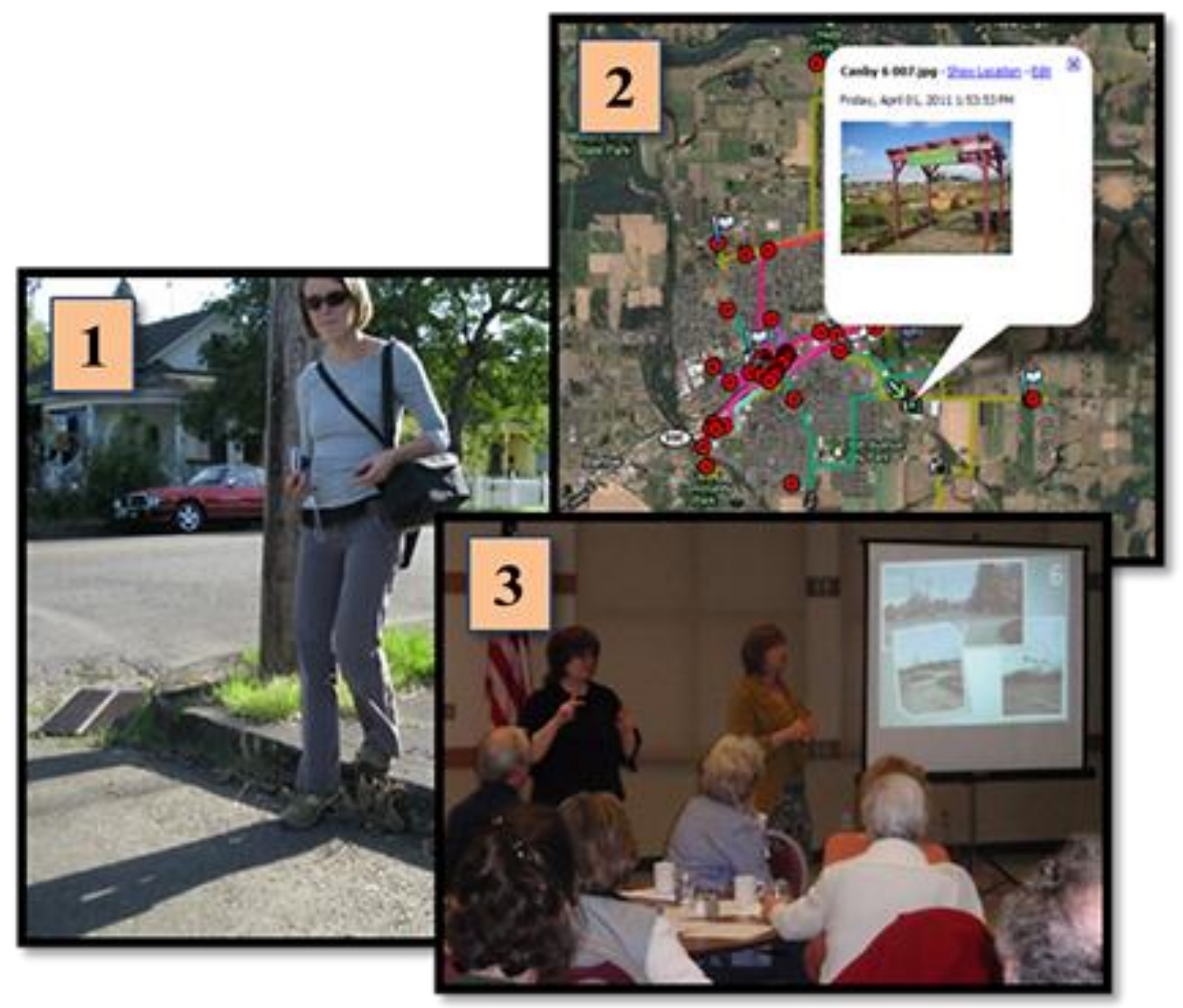

Figure 2 Mapping Assets using Participatory Photographic Surveys (MAPPS ${ }^{\mathrm{TM}}$ ) was facilitated by Cooperative Extension as a component of a county-campus health partnership to support aging friendly communities.

\section{Results}

\subsection{Descriptive Statistics}

Frequency distributions and descriptive statistics for the subsample of older adults are presented in Table 1 . The sample was proportionally distributed between male (46\%) and female (54\%) and the majority of participants reported being white (92.7\%). Most respondents (57.8\%) reported accumulating less than $\$ 50,000$ in household income per year. In addition, $72.9 \%$ of respondents self-reported having good or excellent health. Furthermore, $46.1 \%$ of participants resided in rural $(<10,000$ people) communities. In regard to the outcomes of interest in this investigation, $68.2 \%$ of respondents reported frequently or always participating in exercises to improve their strength and balance, and $41 \%$ of respondents reported frequently or always walking around their neighbourhood. 
Table 1 Demographic information on subsample of older adults $(n=126)$.

\begin{tabular}{|c|c|c|}
\hline Variable & Average/ Proportion & Description of category \\
\hline Age years (SD) & $74.6( \pm 6.9)$ & 65 years or older \\
\hline \multirow[t]{2}{*}{ Sex } & $46.0 \%$ & Male \\
\hline & $54.0 \%$ & Female \\
\hline \multirow[t]{4}{*}{ Race } & $92.7 \%$ & White \\
\hline & $3.3 \%$ & American Indian or Alaskan Native \\
\hline & $3.3 \%$ & Asian \\
\hline & $0.8 \%$ & Black or African-American \\
\hline \multirow[t]{2}{*}{ Ethnicity } & $98.4 \%$ & Not Latino or Hispanic \\
\hline & $1.6 \%$ & Latino or Hispanic \\
\hline \multirow[t]{6}{*}{ Household size } & $34.1 \%$ & 1 person \\
\hline & $56.3 \%$ & 2 people \\
\hline & $5.6 \%$ & 3 people \\
\hline & $2.4 \%$ & 4 people \\
\hline & $0.8 \%$ & 5 people \\
\hline & $0.8 \%$ & 6 people \\
\hline \multirow[t]{4}{*}{ Annual household income } & $26.1 \%$ & $<\$ 25,000$ \\
\hline & $31.7 \%$ & $\$ 25,000$ to $<\$ 50,000$ \\
\hline & $28.5 \%$ & $\$ 50,000$ to $<\$ 100,000$ \\
\hline & $13.5 \%$ & $\geq \$ 100,000$ \\
\hline \multirow[t]{4}{*}{ Health } & $5.6 \%$ & Poor \\
\hline & $21.4 \%$ & Fair \\
\hline & $46.8 \%$ & Good \\
\hline & $26.1 \%$ & Excellent \\
\hline \multirow[t]{5}{*}{ Residency location } & $10.3 \%$ & Urban City / Urban \\
\hline & $43.6 \%$ & Suburban City /Urban \\
\hline & $19.1 \%$ & Small Rural City / Rural \\
\hline & $4.8 \%$ & Small Rural Town / Rural \\
\hline & $22.2 \%$ & Remote / Rural \\
\hline Frequency of walking in & $21.7 \%$ & Never \\
\hline \multirow{3}{*}{ neighborhood } & $37.1 \%$ & Seldom \\
\hline & $32.2 \%$ & Frequently \\
\hline & $8.8 \%$ & Always \\
\hline Frequency of participating & $11.9 \%$ & Never \\
\hline \multirow[t]{3}{*}{ in exercise } & $19.8 \%$ & Seldom \\
\hline & $46.0 \%$ & Frequently \\
\hline & $22.2 \%$ & Always \\
\hline
\end{tabular}




\subsection{Associative Models}

Older adults living in more urban communities reporting good health and higher income had statistically significantly $(p<0.001)$ higher odds of walking around their neighbourhood. The logistic regression model revealed that after controlling for sex, age, health status, and income level, individuals residing in rural communities had $75.6 \%$ lower odds $(p<0.01)$ of walking around their neighbourhood as compared to individuals residing in urban communities. In Model 1, we found that when compared to the lowest annual income $(<\$ 25,000)$ category those in the $>\$ 100,000$ annual income category reported 7.2 times higher odds of walking around their neighbourhood $(p<0.05)$, and those in the $\$ 50,000$ to $<\$ 100,000$ annual income category reported 3.9 times higher odds of walking around their neighbourhood $(p<0.05)$. The 2 nd logistic regression model showed that after controlling for sex, age, health status, and income level, living in rural communities was not associated with higher or lower odds of participating in structured exercise. However, women (vs men) had 2.8 higher odds $(p<0.05)$ of self-reporting participation in exercises to improve their strength and balance. In addition, individuals indicating having good or excellent health (vs individuals reporting fair or poor health) had 3.3 higher odds $(p<0.05)$ of reporting participating in structured exercise. Furthermore, when compared to individuals accumulating below \$25,000 a year in household income, individuals from all higher self-reported income categories had higher odds of participating in exercise to improve strength and balance $(p<0.05)$.

\subsection{Contingency Analyses}

Results of two-way contingency table analyse are presented in Table 2. These analyses were computed to examine the relationships between residential community type (urban, rural) and county population sample's perceptions of availability and importance of physical activity characteristics. For each survey item to which participants responded if they agree or disagree, a follow-up question was asked on how important (very, important, somewhat, not) that characteristic was to them. Response categories were then collapsed into two (upper/lower [i.e. agree/disagree; important/not important]) to account for low numbers of responses in the extremes (e.g. strongly agree/strongly disagree, very/not). Comparisons were run by residential community type (urban/rural) and statistically significant results are bolded. For each significant finding, a greater proportion of respondents in urban compared to rural communities agreed that the age-friendly characteristic was present in their community and/or rated the feature as important to them. In post-hoc analysis Cramer's $V$ was applied showed that the walkability items had a moderate association. The alpha level for all analyses was 0.05 .

A significantly higher percentage of residents from urban compared to rural communities agreed that their community is walkable (67.6\% versus $33 \%$, respectively), yet very few rural (38\%) compared to urban (61.8\%) community residents report walkability as important. A higher proportion of rural residents compared to urban residents (48.6\% versus $31 \%$, respectively) disagreed that available public transportation features were adequate. About twice the proportion of rural (25\%) compared to urban (13.5\%) residents disagreed that a range of outdoor and indoor activities are available in their community although there were no differences in their ratings of importance. The majority of survey respondents agreed that information is available about local services, programs and events, however almost twice as many rural (19\%) compared to urban 
(10\%) residents disagreed. A significantly greater proportion of urban residents rated this to be important compared to rural residents ( $75.4 \%$ versus $64.7 \%$, respectively).

Table 2 Contingency table analyses of population survey of Clackamas County, Oregon adults' differences in perceptions and importance of physical activity and mobility characteristics by residential community (urban, rural) types.

\begin{tabular}{|c|c|c|c|c|}
\hline $\begin{array}{l}\text { Survey Category } \\
\text { Community Characteristic } \\
\text { Importance of Characteristic to Respondent }\end{array}$ & $\begin{array}{l}\text { df, } \\
\mathrm{N}=\text { Valid } \\
\text { Cases }\end{array}$ & $\begin{array}{l}\text { Pearson } \\
\chi^{2}\end{array}$ & $\begin{array}{l}\text { Cramer } \\
\text { 's V }\end{array}$ & $\begin{array}{l}p- \\
\text { value }\end{array}$ \\
\hline Physical Environment & & 45.411 & 0.346 & $<0.001$ \\
\hline Walkable with sidewalks/paths maintained & $2, N=380$ & 30.821 & 0.285 & $<0.001$ \\
\hline This is important to me & $1, N=380$ & 7.496 & 0.141 & 0.024 \\
\hline Accessible public buildings to people with different abilities & 2, $N=379$ & 8.552 & 0.150 & 0.014 \\
\hline This is important to me & $2, N=380$ & 0.083 & 0.015 & 0.773 \\
\hline Roads are adequately marked with visible signs & $1, N=380$ & 0.214 & 0.024 & 0.643 \\
\hline This is important to me & $1, N=380$ & 12.088 & 0.179 & 0.002 \\
\hline Adequate public transportation features & 2, $N=379$ & 2.334 & 0.078 & 0.311 \\
\hline This is important to me & $2, N=380$ & & & \\
\hline Social Environment & & 9.761 & 0.160 & 0.008 \\
\hline Range of outdoor/indoor activities available for all ages & $2, N=380$ & 2.969 & 0.088 & 0.227 \\
\hline This is important to me & $2, N=380$ & & & \\
\hline Service Environment & & 9.439 & 0.158 & 0.009 \\
\hline Local services, programs, events information is available & 2, $N=379$ & 6.322 & 0.129 & 0.042 \\
\hline This is important to me & 2, $N=380$ & & & \\
\hline
\end{tabular}

Note: Degrees of freedom, number of valid cases used in analysis is provided parenthetically for each item. Bolded text indicates items significant at $p<0.05$.

\subsection{Qualitative Findings}

From the six participating communities, 62 volunteer mappers (age 50 years and over) collected data by photographing, mapping (i.e., geotagging), and annotating over 600 environmental attributes they perceived as either supporting or hindering community livability. Data were shared with the entire community through community conversation in each locale. Community stakeholders, including most of the mappers, participated in the community conversations and contributed to the collective narrative by commenting on the quality and spatial distribution of the physical, social and service attributes of their local community. Qualitative data from all sources (e.g., mappers' field and focus group annotations, photographs, and maps; presentation slides and verbatim transcripts of community conversations) depicting subjective qualities of environmental attributes were managed using QSR International's NVivo 10 [26] software.

Initially, two study team members trained in qualitative research methods independently coded data from all qualitative sources, analysed using constant comparison at each conceptual level of influence, and triangulated across quantitative and qualitative data sources. First order coding of data from all sources involved pre-determined categorical nodes. The categories 
represented two community types (rural, urban), three environment types (physical, social, service), and eight attribute topics (i.e. transportation, housing, outdoor spaces and buildings, social participation, respect and inclusion, civic engagement and employment, communication and information, community programs and health services). At least one member of the MAPPS ${ }^{\text {тM }}$ team from the corresponding community verified data by reviewing queries and draft results reports for consistency.

For this study, secondary coding of qualitative data from all sources revealed indicators of specific physical activity behaviours (walk, bike, exercise) and experiences of socio-environmental features (support/make easy, barrier/make hard). Themes emerged from data queries in community environment categories for walking (supports; barriers) and exercise (supports; barriers). Results are presented in Table 3.

Table 3 Physical, social, and service environment supports and barriers for walking and exercise.

\begin{tabular}{|c|c|c|}
\hline $\begin{array}{l}\text { Environment } \\
\text { Category }\end{array}$ & $\begin{array}{l}\text { Thematic Supports } \\
\text { W=Walking } \\
E=\text { Exercise }\end{array}$ & $\begin{array}{l}\text { Thematic Barriers } \\
\text { W=Walking } \\
\mathrm{E}=\text { Exercise }\end{array}$ \\
\hline $\begin{array}{l}\text { Physical/ } \\
\text { Structural }\end{array}$ & $\begin{array}{l}\text { - } \text { Active (walk/bike) transportation } \\
\text { system/plan (W,E) } \\
\text { - Pedestrian/bicyclist safety (W,E) } \\
\text { - Walkability (W) } \\
\text { - Gardens, parks, green space (W,E) } \\
\text { - Community/recreation center (E) }\end{array}$ & $\begin{array}{l}\text { - Pedestrian/bicyclist safety (W,E) } \\
\text { - Automobile dependence (W,E) } \\
\text { - Crime and safety (W,E) } \\
\text { - Disconnected, poorly maintained, } \\
\text { unlit sidewalks, paths, trails (W) }\end{array}$ \\
\hline Social & $\begin{array}{l}\text { - Community/recreation center (E) } \\
\text { - Walking/exercise groups }(W, E)\end{array}$ & $\begin{array}{l}\text { - Community safety/criminal } \\
\text { activity }(\mathrm{W}, \mathrm{E}) \\
\text { - Community/recreation center } \\
\text { (E) }\end{array}$ \\
\hline Service & $\begin{array}{l}\text { - Community/recreation center (E) } \\
\text { - Public transportation (W) }\end{array}$ & $\begin{array}{l}\text { - Community/recreation center } \\
\text { (E) } \\
\text { - Public transportation (W) }\end{array}$ \\
\hline
\end{tabular}

Note: Bold indicates theme emerged as both a support and barrier.

Community projects from urban $(n=3)$ and rural communities $(n=3)$ were merged to allow for queries by coded type (urban; rural) and reveal differences in residents' perceptions of community characteristics as an aspect of urban or rural. Data queried by type included geo-located photographs of physical activity supports or barriers in the community as experienced by residents and explained through coded narratives. Results revealed different walkability/active aging aspects of urban and rural communities. Content analyses revealed residents experienced rural communities as having fewer available, accessible, and affordable walking/biking or exercising options, and more environmental obstacles to active aging than urban communities. 


\section{Interpretation}

Mixed methods triangulation allowed a comparison of the findings from different data sources and methods of data collection [27]. Triangulation also allowed comparison among communities to reveal similarities and differences, develop and/or substantiate our overall interpretation. To explore the interplay between attributes of older people, including disparities in physical activity behaviour within and between groups, and environmental assets in communities, we integrated and interpreted quantitative and qualitative findings in relationship to our conceptual framework. Unsurprisingly, county-residing adults differently perceived the availability of structural, social, and policy-supported services and environmental features related to physically active aging depending on their residential location (urban or rural). Data from MAPPS ${ }^{\mathrm{TM}}$ projects in local communities corroborated survey findings. Rural residents explained actual experiences of their local communities as having fewer available walking and exercise assets. Personal factors, such as income and ability, often determined whether a resident attributed an available community feature as a support (makes physically active aging easier) or barrier. Findings revealed key considerations when advocating for improvements to the physical activity context, such as considering differences in attributes within and between groups (e.g. income and health status among older women living in rural and urban places), which may help determine environmental supports that will most easily support physically active aging for those chronically deprived of physical activity resources.

Supportive structural, social and policy environments contributed to the ability of people to exercise, walk, "wheel," and bike for exercise and/or to destinations in their community as endorsed by the U.S. Surgeon General [3]. Rural communities were experienced as having fewer supports (see Figure 3), which provided an explanation why people living in rural places were less likely to walk around their neighbourhoods. Fan and colleagues found within rural areas, micropolitan residents were less active than residents in smaller rural areas [4]. Compared to urban dwellers, rural residents spent more time in low-intensity household physical activity but less time in high-intensity physical activity [4]. Our integration of quantitative and qualitative data helped reveal that in the absence of structural supports for walking, rural people who reported more personal resources (e.g. money, time, good health, motivation) found ways to age actively despite the lack of place-based, environmental supports. Under-resourced older rural people depended on no/low cost local programs and sustained community services for physical activity and other (i.e. transportation) active aging enablers.

In this study, we examined the interplay between the attributes of independently living older adults, their physical activity behaviours, and the community place where they reside. We learned that older people encountered and rural communities presented more obstacles to being active in older age and fewer no/low cost options for exercise and walking. This highlights a gap in access to resources and provides rationale to address personal and environmental needs of the population that habitually exhibits the lowest levels of physical activity [2] (see Figure 4). 


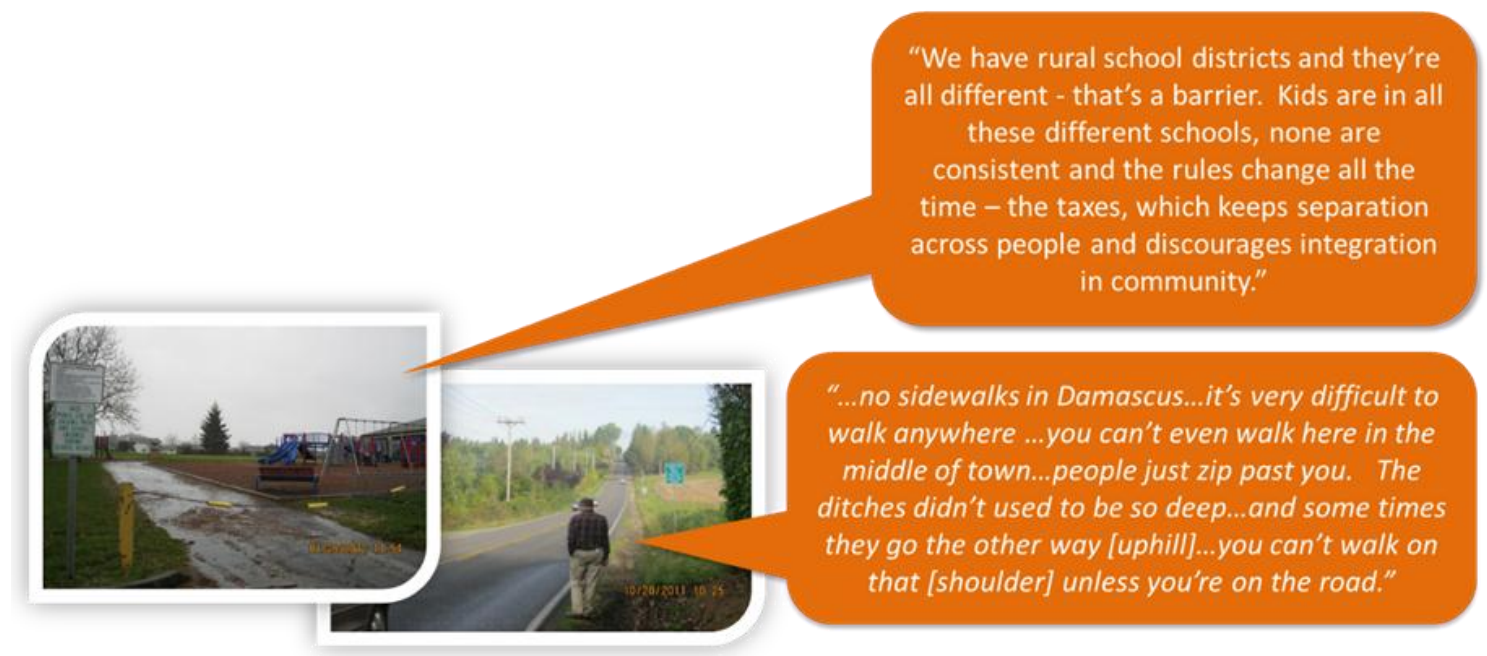

Figure 3 People living in rural communities had lower odds of walking around their neighborhoods, which were less supportive of walking for exercise or transportation.
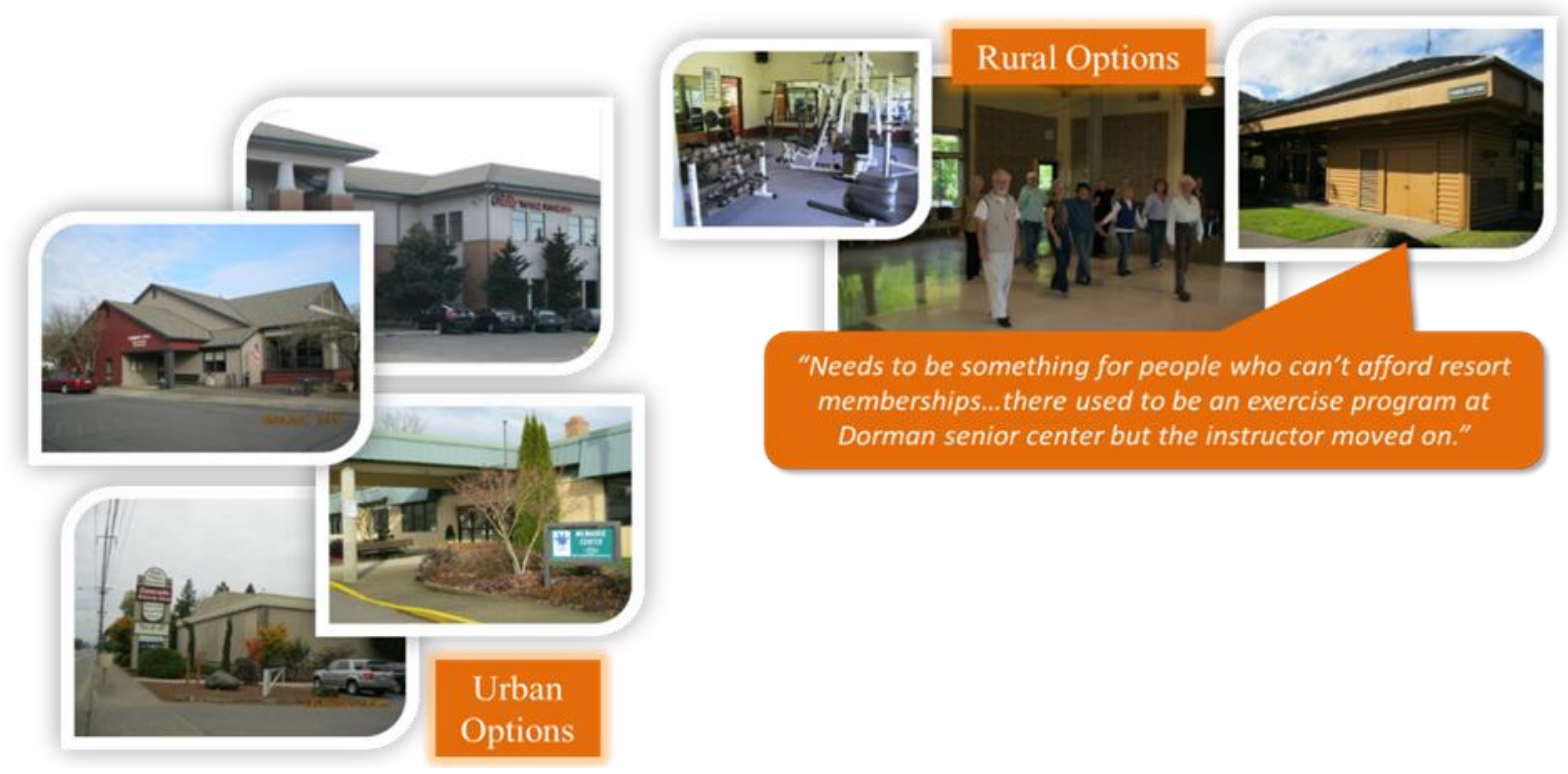

Figure 4 Healthy, older women of higher income had higher odds of participating in strength and balance exercise; however, community-based options were underresourced or not available in rural communities.

\section{Conclusions}

By using a mixed methods approach, we were able interpret the interplay between physical activity attributes of older adults and their community context, and better understand how walking and other exercise behaviours may be influenced by these interrelated factors. Importantly, we learned why exercise, walking for recreation, and active transportation are easier to achieve for some people and harder for others. Specifically, we learned differences in quality, quantity, accessibility, and cost of available physical activity options vary by community classification as rural versus urban, and that these differences impact residents' physical activity behaviours, particularly among those living rurally with lower income and poorer health status. 
These findings advance knowledge about physically active aging and associated socioenvironmental barriers, and provide information useful to policy makers and practitioners. In the U.S., physical activity recommendations include that all people, of every age and ability, have “...well-maintained sidewalks, pedestrian-friendly streets, access to public transit, adequate lighting, and desirable destinations that are close to home [...]" [3]. Our findings support the work of others $[11,14,18]$, if we are to meet recommendations, close the inactivity gap in older, limited resource populations, and address rurality as a health disparity, we must engage residents and communities in solutions that are locally determined as important, sustainably resourced, and easily accessible and affordable to those with fewest resources. Initiatives for promoting physical activity as a prevention strategy, especially those promoting daily activity as something everyone should do, must consider availability and accessibility of proximal physical activity supports, walkability and active transportation features. Finally, we need to work collaboratively with intention across sectors to improve the community context to equitably support physically active as an inclusive, health protective behaviour that is justly available to all people in all places.

\section{Acknowledgments}

We would like to acknowledge the project partners, Clackamas County Social Services and AARP Oregon, and community collaborators for your dedication to creating "age-friendly," liveable communities for all ages.

\section{Author Contributions}

Each author's major contribution to this work is specified respectively. DHJ designed study, analysed qualitative data, drafted the manuscript, and provided data for Table 3, PN conducted all statistical analyses reported in Table 1 and Table 2, and KG provided substantial analytic and revision contributions. All authors reviewed the final manuscript.

\section{Competing Interests}

The authors have declared that no competing interests exist.

\section{References}

1. World Health Organization. Information sheet: Global recommendations on physical activity for health 65 years and above; 2011. Retrieved from: http://www.who.int/dietphysicalactivity/publications/recommendations65yearsold/en/.

2. Office of Disease Prevention and Health Promotion. Physical activity. In Healthy People 2020; 2016. Retrieved from: https://www.healthypeople.gov/2020/topicsobjectives/topic/physical-activity.

3. U.S. Department of Health and Human Services. Step it up! The surgeon general's call to action to promote walking and walkable communities; 2015. Retrieved from: http://www.surgeongeneral.gov/library/calls/walking-and-walkable-communities/.

4. Fan JX, Wen M, Kowaleski-Jones L. Rural-urban differences in objective and subjective measures of physical activity: Findings from the National Health and Nutrition Examination Survey (NHANES) 2003-2006. Prev Chronic Dis. 2014; 11: 140189. 
5. Centers for Disease Control and Prevention. National Center for Chronic Disease Prevention and Health Promotion, Division of Nutrition, Physical Activity, and Obesity. Data, Trend and Maps; 2018. Available from: https://www.cdc.gov/nccdphp/dnpao/data-trendsmaps/index.html.

6. Oregon Department of Human Services. Healthy Aging in Oregon Counties; 2009. Available from: $\quad$ http://public.health.oregon.gov/DiseasesConditions/ChronicDisease/Pages/ healthyaginginoregoncounties.aspx.

7. Farber N, Shingle D. Aging in place: A state survey of livability policies and practices. Washington: AARP Public Policy Institute (US); 2011. Available from: http://www.aarp.org/home-garden/livable-communities/info-11-2011/Aging-In-Place.html.

8. U.S. Department of Agriculture; USDA. Economic Research Service. 2004 County Typology Codes; 2004. Available from: http://www.ers.usda.gov/data-products/county-typologycodes.aspx.

9. U. S. Department of Agriculture; USDA. National Agriculture Library. What is Rural. 2008. Available from: http://www.nal.usda.gov/ric/ricpubs/what is rural.shtml\#intro.

10. Oregon Office of Rural Health. Areas of Unmet Health Care Need in Rural Oregon Report. 2013. Available from: http://www.ohsu.edu/xd/outreach/oregon-rural-health/data/healthcare-shortage.cfm.

11. Srinivasan S, Liam R, O'Fallon L, Dearry A. Creating healthy communities, healthy homes, healthy people: Initiating a research agenda on the built environment and public health. Am J Public Health. 2003; 93: 1446-1450.

12. Stokols D. Translating social ecological theory into guidelines for community health promotion. Am J Health Promot. 1996; 10: 282-298.

13. Maibach E, Abroms L, Marosits M. Communication and marketing as tools to cultivate the public's health: A proposed "People and Places" framework. BMC Public Health. 2007; 7: 88.

14. John D, Gunter K. engAGE in community: Using mixed methods to mobilize older people to elucidate the age-friendly attributes of urban and rural places. J Appl Gerontol. 2016; 35: 1095-1120.

15. Creswell JW, Plano Clark VL. Choosing a mixed method design. In Designing and Conducting Mixed Methods Research. Thousand Oaks: Sage Publications; 2011.

16. World Health. Global age-friendly cities: A guide. 2007. Retrieved from: http://www.who.int/ageing/publications/Global age friendly cities Guide English.pdf.

17. Viswanathan M, Ammerman A, Eng E, Gartlehner G, Lohr KN, Griffith D, et al. Communitybased participatory research: Assessing the evidence. Summary, evidence report/technology assessment No. 99. Rockville: Agency for Healthcare Research and Quality; 2004.

18. Federal/Provincial/Territorial Ministers Responsible for Seniors (F/P/T). Age-friendly rural and remote communities: A guide. Ottawa, Canada: Public Health Agency of Canada, Division of Aging Services; 2007. Available from: http://www.phac-aspc.gc.ca/seniorsaines/publications/public/afc-caa/rural-rurales/index-eng.php.

19. Centers for Disease Control and Prevention (CDC). Behavioral risk factor surveillance system survey questionnaire. Atlanta: U.S. Department of Health and Human Services; 2010. Available from: http://www.cdc.gov/brfss/questionnaires.htm.

20. StataCorp. Stata statistical software: Release 12. College Station: StataCorp LP; 2011. 
21. Dennis S, Gaulocher S, Carpiano R, Brown D. Participatory photo mapping (PPM): Exploring an integrated method for health and place research with young people. Health Place. 2009; 15: 466-473.

22. Carr D, Halvorsen K. An evaluation of three democratic, community-based approaches to citizen participation: Surveys, conversations with community groups, and community dinners. Soc Natur Resour. 2001; 14: 107-126.

23. Edwards RW, Jumper-Thurman P, Plested BA, Oetting ER, Swanson L. Community readiness: Research to practice. J Community Psychol. 2000; 28: 291-307.

24. John D, McCahan B, Gaulocher S. Partnering to enable active rural living: PEARL project. J Rural Soc Sci. 2012; 27: 74-101.

25. Franz N. The data party: Involving stakeholders in meaningful data analysis. J Extension. 2013; 51. Available from http://www.joe.org/joe/2013february/iw2.php.

26. NVivo qualitative data analysis Software; QSR International Pty Ltd. Version 10, 2012.

27. Pope $C$, Mays N. Reaching the parts other methods cannot reach: An introduction to qualitative methods in health and health services research. Brit Med J. 1995; 311: 42-45.



Enjoy OBM Geriatrics by:

1. Submitting a manuscript

2. Joining in volunteer reviewer bank

3. Joining Editorial Board

4. Guest editing a special issue

For more details, please visit: http://www.lidsen.com/journals/geriatrics 